\title{
The design of the industry chain model of energy saving service based on Energy Management Contract
}

\author{
Du Juan \\ School of Economic and Management \\ Changchun University of Technology \\ Changchun, Jilin, China
}

\author{
Song Junbiao \\ School of Economic and Management \\ Changchun University of Technology \\ Changchun, Jilin, China
}

\begin{abstract}
China introduced the Energy Management Contract which is a kind of energy saving service mechanism based on the market to improve the efficiency of energy utilization and reduce the energy consumption. Through the Energy Management Contract mechanism, China can transform the original goverment behavior, the promotion of the reduction of energy conservation and emission in the enterprises, into the enterprise and market behavior. Therefore, the implementation of Energy Management Contract is bound to bring the development of a new energy saving service industry chain. At present, relevant researches on the energy saving service industry are rarely related to the composition of the energy saving service industry chain or the descriptions of the constitution of the chain are not comprehensive enough. So, from the perspective of industry chain, we consider the energy service companies based on EMC mechanism as the center and analyze the links with other enterprises in the process of their development. Then we design the industry chain model of energy saving service based on Energy Management Contract. We expect the model can provide theoretical support for our follow-up research of energy service industry.
\end{abstract}

Keywords - Energy Management Contract; Energy saving service industry; industry chain; model

\section{ENERGY SAVING SERVICE INDUSTRY AND ENERGY MANAGEMENT CONTRACT}

\section{A. The emergence of energy saving service industry in China}

With the countries all over the world developing their economies, the problem of energy consumption has become increasingly prominent. In the 1970s, after the outbreak of the oil crisis in the world, to meet the needs of modern enterprises for the professional and socialized production and service and alleviate the problem of energy shortage in a certain extent ${ }^{[1]}$, Energy Management Contract(EMC), as a new mechanism of energy saving, gradually emerged in the countries which ware economically developed. In 1990s, China introduced and promoted this market-based mechanism which integrates energy saving investment and service. In 1998, China implemented the "World Bank-Global Evironment Facility (GEF) China Energy Conservation Promotion Project", associated with the World Bank and the Global Environment Facility, jointly set up three demonstrations of
Energy Service Corporation In Beijing, Liaoning and Shandong provinces to explore the commercial operation of energy management contract by the aid of the world bank loan ${ }^{2]}$. The government of China attached great importance to the development of energy saving service industry. Since the introduction of Energy Management Contract mechanism, in order to guide and promote it, the government of China has published a number of relevant policy documents. During The Communist Party of China's 18th Central Committee in 2015, China proposed to establish the concept of green development, control energy consumption and intensity and continually promote Energy Management Contract. Last year, when Xi Jinping, the president of China, participated in the United Nations Climate Change Conference, he repeatedly expressed the determination and confidence of China in implementing the energy saving and environmental protection to the countries all over the world. So, it was an opportunity and a challenge to the energy saving service industry in China.

\section{B. The Operational Mechanism of Energy Management Contract}

Energy Management Contract is a kind of commercial mechanism in which the Energy Service Corporation(ESCO) signs an "energy management contract" with the energy consumption unit, with a certain amount of energy saving as the goal, the ESCO provides a series of services to the energy consumption unit, and then recover the investment and obtain a reasonable profit from the efficiency of energy serving. The essence of Energy Management mechanism is a kind of energy saving investment which allows the energy consumption units to pay the total cost of energy saving projects by the reduction of their cost of energy expenditure, allows the energy consumption units to utilize the future energy saving benefits to upgrade equipment, reduce their operating costs and improve energy efficiency ${ }^{[3]}$. In general, during the "energy management contract" period, the income of the ESCO has a positive relationship with the energy saving efficiency achieved by it. By the end of the "energy mananement contract", the energy consumption units will be able to gain all of the energy saving benefits and energy saving equipment, as well as the relevant technologies. As for the ESCO which is the carrier of EMC is a kind of specialized service company based on the EMC mode.Generally speaki- 
ng, The EMC mode points out the specific way for the industrialization of the energy conservation service market.

\section{The ANALYSIS OF ENERgy SAVING SERVICE INDUSTRY}

\section{A. The analysis of the business process of the Energy Service Corporation}

The ESCO firstly selects and makes contact with the energy consumption unit. Then it will provide the services of energy saving diagnosis and the design of energy saving reclaim plan to the the energy consumption unit which has the intention of energy saving. When the energy consumption unit agrees the ESCO to implement energy saving reclaim for it, the ESCO will sign an "energy management contract" with the energy consumption unit, then provides a series of services to the unit, such as the financing of energy saving project, the procurement of raw materials and equipment, engineering construction, the installation and debugging of the equipment, personnel training and the operation and maintenance of the equipment, monitoring the amount of energy saving, the management of the project operation and so on. During the contract period the ESCO guarantees to achieve a certain amount of energy conservation agreed in the "energy management contract" and recovers investment and obtains a reasonable profit an the same time. At the expiration of the contract, the ownership of the energy saving project will be transferred from the ESCO to the energy consumption unit. The business process of the Energy Service Corporation is given in chart I .

1) Select and contact the energy consumption unit. The ESCO selects and contacts the energy consumption unit which has low energy utilization efficiency or high energy consumption and understands the operational performance of the energy consumption unit and the operating condition of its energy utilization system preliminarily. Additionally, the ESCO needs to illustrates its business operation mode to the unit and points out it's general energy saving potential. Then ESCO proposes the solutions of energy saving and estimates the general benefits will be achieved by the energy saving reclaim. It is also necessary that the ESCO explains the relevant issues of Energy Management Contract mechanism to the unit and makes sure of it's energy saving intention.

2) Energy saving diagnosis. After confirming that the energy consumption unit has the intention to carry out energy saving reclaim, the ESCO will send professionals to conduct testing, verification, analysis and evaluation to the energy using equipment and the entire process of the energy utilization of the energy consumption unit. Then the professionals will determine its current level of energy consumption and evaluate whether its current energy utilization is scientific and reasonable or not and point out the specific energy saving potential.

3) Design the energy saving reclaim plan. After energy saving diagnosis, the ESCO offers the service of designing energy saving reclaim plan to the energy consumption unit and ensures that the unit can fully understand the process and effect of the energy saving renovation. The plan includes the
CHART I. Business Processes of The Energy SERVICE Corporation

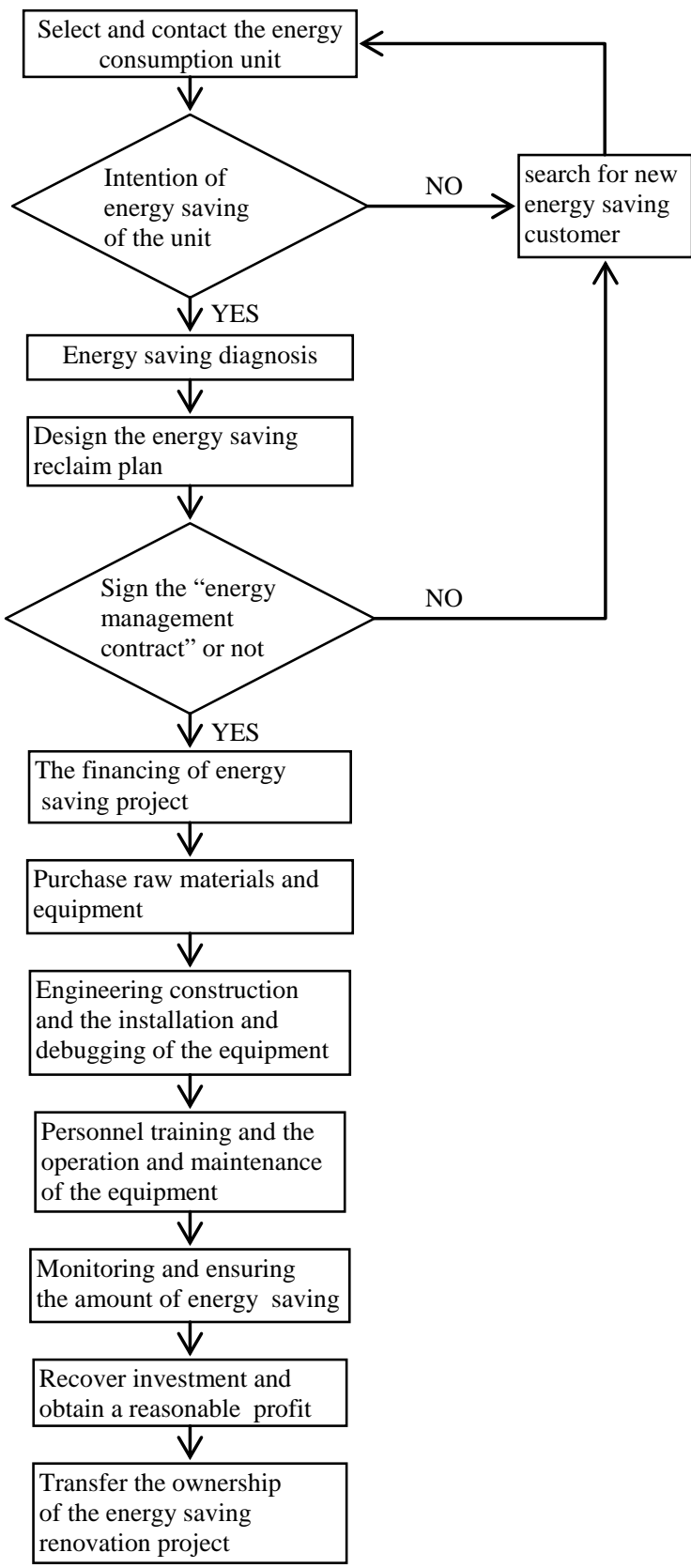

implementation scheme of energy saving reconstruction project and the analysis and forecast of the energy saving efficiency that the energy saving reclaim can realize.

4) Sign the "energy management contract". If the energy consumption unit accepts the energy saving reclaim plan, the ESCO will negotiate with it about the items of the contract. In the contract, they protocol the time of energy management, responsibilities and obligations of both parties during the contract period, the energy saving benefits realized through energy saving renovation, specify the method of monitoring energy saving performance and the standard of measuring the amount of energy saving and how to distribute the benefits of energy saving, etc. When the two sides reached a consensus, 
it's time for them to sign the "energy management contract".

5) The financing of energy saving project. Usually, in the process of ESCO providing energy saving transformation services to the energy consumption unit, the customer doesn't need to undertake any cost required for the implementation of energy saving project, all the costs are paid by the ESCO. So, before the launch of energy conservation renovation project, the ESCO firstly needs to complete the task of financing for the energy saving renovation project.

6) Purchase raw materials and equipment. According to the energy saving reclaim plan, ESCO purchases raw materials and related energy saving equipment.

7) Engineering construction and the installation and debugging of the equipment. ESCO is responsible for organizing the engineering construction related to the energy saving renovation project and accomplishes the installation and debugging of the energy saving equipment.

8) Personnel training and the operation and maintenance of the equipment. Although the energy saving reclaim plan is based on the energy saving diagnosis, in the practical operation of the energy utilization system, the energy saving performance predicted by the ESCO may not be achieved for a long term. Because the the quality and longtime maintenance of the energy saving equipment have essential effects on the ultimate energy saving performance. So, the ESCO needs to train the relevant staff members of the energy consumption unit, prepare the manual refers to the operation and maintenance of the equipment and make sure that the related operators are able to operate and maintain the equipment correctly in the actual operation. In addition, the ESCO also needs to organize personnel to carry out on-site management and regular inspection of the energy saving equipment.

9) Monitoring and ensuring the amount of energy saving. After the operation of energy saving equipment, the ESCO and energy saving customer need actually monitor the amount and the benefits of energy saving in accordance with the the manner agreed in the "energy management contract". If necessary, they can entrust the authoritative institution of authentication and appraisal to confirm the amount of energy saving achieved by energy saving renovation project and take the result as the basis for the allocation of the energy saving efficiency.

10) Recover investment and obtain a reasonable profit. According to the actual energy saving efficiency measured by both the ESCO and the energy consumption unit or the authoritative institution of authentication and appraisal and the distribution manner prescribed in the "energy management contract”, they share the benefits of energy saving. The ESCO recycles its investment from the entire energy saving renovation project and obtains a reasonable profit mainly by the distribution of energy saving profits.

11) Transfer the ownership of the energy saving renovation project. Within the period of the "energy management contract”, the ESCO has the ownership of the investment related to the energy saving renovation project, such as raw materials, engineering construction, energy saving equipment and energy saving technologies, etc. But at the end of the contract the ownership will be transferred to the energy saving customer without any conditions. Then the the energy consumption unit will not only gain the ownership of the energy saving renovation project but also can share all the benefits achieved by energy saving reclaim alone.

\section{B. The analysis of external entities of the operational Energy Service Corporation}

In China, improving energy efficiency is an important part of the construction of ecological civilization. Since China introduced EMC, the energy saving service industry has made a great contribution to the green and low-carbon environmental development in less than 20 years. "In the global energy saving, China has contributed to $1 / 2$, energy saving service industry takes up the main part”, Du Xiangwan, former vice president of the Chinese Academy of Engineering said at the "2015 ESCO SUMMIT" held in Beijing. According to the statistics of ESCO Committee of China Energy Conservation Association(EMCA) in 2015, to the end of "12th Five-Year Plan", the total number of enterprises engaged in energy saving services reached to 5426 in China, nearly 6 times more than the number of the end of the "11th Five-Year Plan". The total output value of the energy saving service industry increased from ¥83.629 billion in 2010 to $¥ 312.734$ billion. At the end of 2015, the number of the ESCO whose total output value is more than $¥ 1$ billion is 25 , more than $¥ 0.5$ billion is 142 and more than $¥ 0.1$ billion is 286 . These data reflect the current situation that the energy saving service industry of China is booming. However, due to the short time of the development in the energy saving field of China, at present, most ESCOs in China's energy saving service market are small and medium enterprises which lack of funds and technologies. In addition to the needs for national policy supports, we think the more important is that these enterprises achieve rapid development through their own efforts.

Nowadays, the ESCO may not have the capacity to provide professional services to the the energy consumption unit in the entire process of energy saving reclaim. But if the ESCO use the external resources of the enterprise effectively, it can also realize the energy saving efficiency guaranteed in the "energy management contract". The ESCO can obtain new energy saving technologies from research center, universities or other research institutions, can design professional "energy management contract" with the help of the judicial brunches, can apply for investments from the energy saving investment institutions or loan to the bank via the government or the guarantee corporations, can purchase advanced energy saving equipment from the energy saving equipment manufacturers, can buy the energy saving products from the energy saving products suppliers, can sign the insurance contracts with the insurance company to decrease investment risk, can gain more specialized construction scheme provided by the engineering design units, can select a qualified construction enterprise to finish the part of the engineering construction of the energy saving project by the way of bidding and 
can seek advice from the energy saving service consulting company or the other advisory service agencies to solve the problems encountered in the implementation of the energy saving renovation project. The ESCO which relies on the EMC mode and linked to the energy consumption unit is like a conversion platform, it provides satisfactory energy saving service to the energy consumption unit by integrating the characteristics of itself and the specialized abilities of the above organizations.

In China, the industry, construction industry and transportation industry are the three major areas of energy consumption and the industrial energy consumption accounts for the highest proportion among them. During the "11th Five-Year Plan" and "12th Five-Year Plan" period, the Chinese government set strict energy saving targets to those high energy consuming industrial industries such as iron and steel industry, nonferrous metals industry, building materials industry, petrochemical industry, chemical industry, electric power industry, light industry and textile industry and so on. Corresponding to this, the energy service market is also concentrated in the industrial field. This year is the first year of the "13th Five-Year Plan", with the development strategy of building a well-off society in an all-round way, the proportion of building energy consumption of China's total energy consumption will continue to increase. So the energy conservation needs of building area will be further expanded. Additionally, the government agencies, existing residential buildings, office buildings and public buildings also have great potentials of energy saving. Therefore, in the implementation of the "13th Five-Year Plan", with the continuous promotion of energy conservation, energy saving services will continue to focus on the industrial energy saving field and make considerable progress in the areas of building and traffic energy conservation, particularly in the energy saving of government agencies and existing buildings. The energy service market will expand in crossrange and the fields of energy saving service will tend to balance. Visibly, in China the energy service industry based on EMC has a broad customer group.

\section{THE INDUSTRY CHAin MOdEL OF ENERgy SAVING SERVICE BASED ON EMC}

The industry chain is a intermediate organization between the perfectly competitive market organization and the organization of grade system. The essence of the industry chain is linking up the principal values which determine and affect the final products of the industry by value ${ }^{[5]}$. We refer to relevant literature to define the industry chain as follows: industry chain is based on Michael E.Porter's value chain theory, in a certain geographical area, it takes a competitive or competitively potential enterprise as the core of a certain industry; it operates around the capital, product, technology or business, divides the labor via technology or function and constitutes different enterprises to a chain with value added function. Industry chain is the connection between independent enterprises.In today's world, the market competition is not only the competition between enterprises, what's more is the competition between one industry chain and another. Forming industry chain is an effective choice for enterprises to maximize the common interests ${ }^{[6]}$ and enables enterprises to reduce trade costs and operational risks, get new key resources, enhance the competitive advantage, develop new market, maintain and expand the market share.

Industry chain generally consists of upstream suppliers, core enterprises, downstream sellers and ultimate consumers. Therefore, according to Michael E.Porter's value chain theory, we respectively analyze the relationship between the ESCO and other enterprises or units when the ESCO is at the demand side and the supply side. We extract various kinds of ESCOs to form the middle-stream service provider which is the core enterprise of the industry chain model designed in this paper. Extract the enterprises or institutions which provide direct support to the ESCOs to constitute the upstream supplier. Extract the service objects of the ESCOs to constitute the downstream customer. Finally, we extract the institutions which provide supervision and indirectly support as the third-part organization. The industry chain model of energy saving service based on EMC is given in chart II .

1) Upstream supplier. The upstream supplier consists of various kinds of energy saving products and equipment manufacturing enterprises, energy saving technology research institutions and energy saving investment institutions and so on. The suppliers can provide energy saving products, equipment, technologies and capital needed in energy saving reclaim project. They are located on the upper reaches of the industry chain model of energy saving service based on EMC.The upstream suppliers are not directly involved in the energy saving renovation. When energy saving reclaim is carried out independently by the energy consumption unit, the suppliers can offer the needed equipment and technologies then obtain a certain reward. When the renovation is implemented by the ESCO, the suppliers can provide these to the ESCO, then the EMCo conduct related services of energy saving for the energy saving unit.

2) Middle-stream service provider. The middle-stream service provider consists of all kinds of ESCOs based on the EMC mechanism. When the ESCOs undertake the energy saving renovation project of the customers, they can take advantage of the energy saving products, equipment, technologies and capital from the upstream suppliers and conduct the energy saving renovation for the customers. In the energy saving service industry chain based on EMC, the ESCOs are the suppliers of energy saving service.

3) Downstream customer. The downstream customer consiets of various energy consumption unit. Some energy consumption industries and institutions extremely need to reduce the amount of energy utilization and improve their energy utilization efficiency via energy saving reclaim.By purchasing energy saving equipment, products and technologies from the upstream suppliers they can implement the renovation independently. Moreover, they can outsource the energy saving projects to the ESCOs. When the energy consumption units outsource the energy saving project to the EMCOs,they are the consumers of energy saving service in the saving service industry chain based on EMC.

4) The third-part organization. The third-part organizati- 
CHART II. THE INDUSTRY CHAIN MODEL OF ENERGY SAVING SERVICE BASED ON EMC

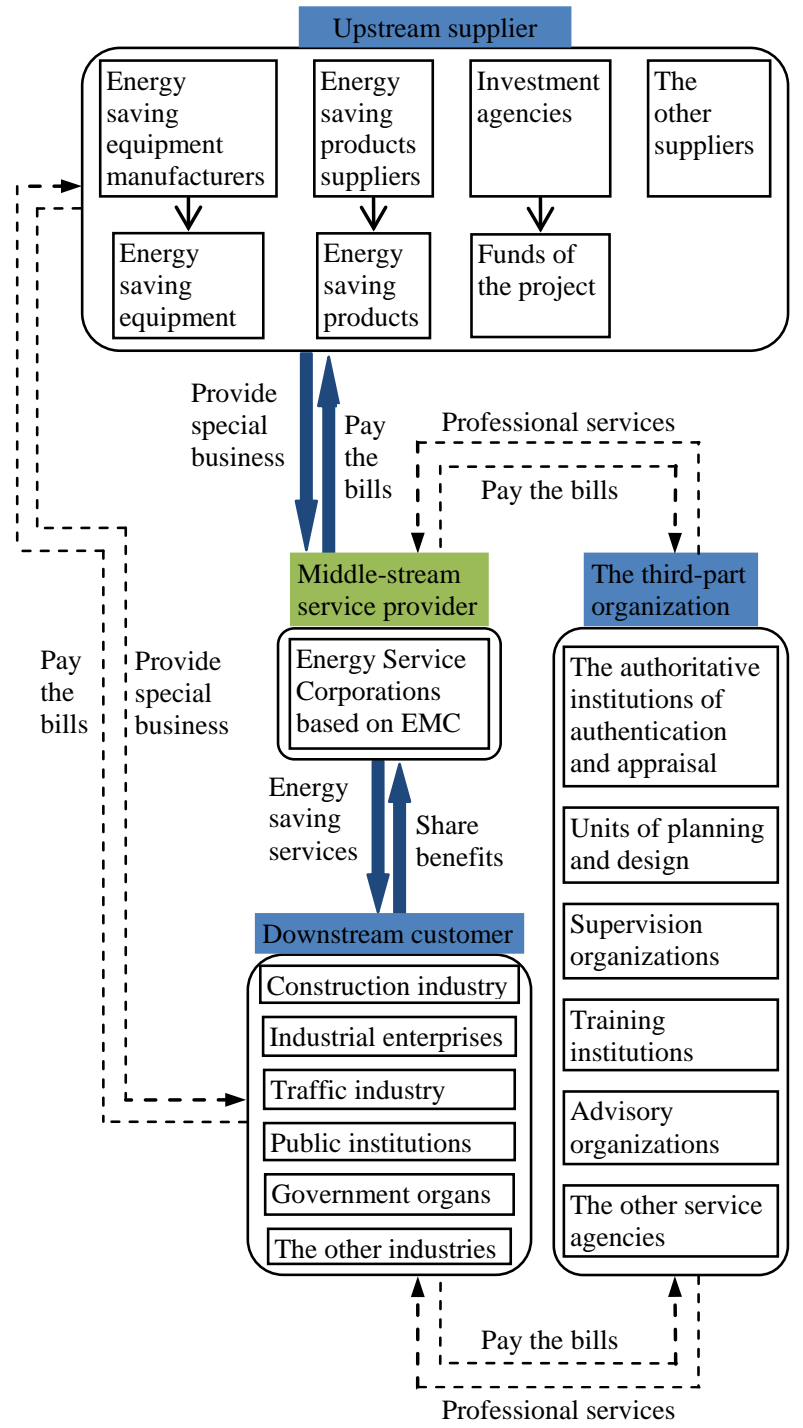

on consists of the authoritative institutions of authentication and appraisal, planning and design institutions, supervision agencies, training institutions, advisory bodies and other services related to the energy saving reclaim. They mainly provide supports of personnel, knowledge, technologies and authoritative certifications to the reclaim and then get a certain reward. For example, at the end of the project, if the two sides have arguments on the actual energy efficiency, they can take the energy saving efficiency measured by the authoritative institution of authentication and appraisal as the standard. Whether the the energy consumption unit or the ESCO carries out the energy saving project, both of them can successfully reduce energy consumption more scientifically with the help of the third-part organizations. The existence of the third-part organizations has a positive role in building a healthy and orderly energy saving service market.
Under the background of the increasingly serious global energy problem, it is imperative for China to carry out energy saving works in the whole society. From the introduction of energy saving service industry chain described above, you will find that the the energy consumption unit can implement the energy saving project independently. However, it will undoubtedly occupy the funds of it and divert its attention on the main business. What needs attention is that there is also a certain degree of risk in the energy saving reclaim project. Instead, the ESCO can burden the pressures and risks of energy saving reclaim, while the energy consumption unit focuses on market competition and its development of core competitiveness. Furthermore, there is also no need of investment from the energy consumption unit. We think this is the main reason for the promotion of EMC. It can be said that the implementation of EMC mechanism creates possibility to the establishment of the standardized energy saving service market for China.

\section{CONCLUSION}

China has a huge potential in the energy conservation field, but the energy saving service industry is just a new. At present, the existing industry scale is still far from meeting the broad demand. The development experience of foreign energy saving service industry shows that the government plays a leading role in the development of it. With the development and growth of the energy saving service enterprises, they will turn from being government-oriented to marketoriented $^{[7]}$. Therefore, the development of the energy saving service industry needs the supports of relevant policies and regulations published by the government. What's more, the ESCOs must strive to do well in the improvement of themselves, seize market opportunity, integrate the powers of the energy saving service industry chain and concentrate major resources on improving the specialized level of core business capacity. We think that's the way to realize the vigorous growth of energy saving service industry and achieve the goal of improving energy utilization efficiency and reducing the total energy consumption for China.

\section{REFERENCES}

[1] Zhangli, "The implementation of contract energy management and development of energy saving service industry,” Journal of Hubei University of Economics:Humanities and Social Sciences, China, Vol. 11, pp. 24-26, December 2014.

[2] Kang Yanbing, Zhangyang, and Yin Zhifang, "Developing status and prospect of China's energy service industry,” Energy of China, China, Vol. 8, pp. 29-32, January 2011.

[3] Chen Liuqin, "Energy management contract:innovating energy-saving business model,” Hydropwer and New Energy, China, Vol. 1, pp. 1-6, July 2012.

[4] Zhou Xinsheng, "Chain of Industries and Its Formation," Social Sciences in Guangdong, China, Vol. 4, pp. 30-36, August 2006.

[5] Huangling, and Wang Yihua, "Theoretical and model analysis of Transnational Strategic Alliance,” Regional Economic Review, China, Vol. 11, pp. 56-57, December 2004.

[6] Zhanghong, "Comparative study on energy saving service system at home and abroad,” Market Modernization, China, Vol. 28, pp. 94-95, December 2012. 